\title{
Modeling and optimization of SOFC based on Metaheuristics
}

\author{
Qixiang $W u^{1, *}$, Mohammadreza Shafiee ${ }^{2}$ \\ ${ }^{1}$ Media Design Department, Woosong University, Daejeon, Republic of Korea \\ ${ }^{2}$ Semnan University, Semnan, Iran \\ *E-mail: shiping1737@163.com, shafiee21@gmail.com
}

doi: $10.20964 / 2020.11 .01$

Received: 9 April 2020 / Accepted: 13 August 2020 / Published: 30 September 2020

\begin{abstract}
This study proposed a well-organized technique for the optimal selection of the unknown parameters for the Solid Oxide Fuel Cell (SOFC) model. The main idea is to propose a new metaheuristic method to achieve more efficient results for the model to give a satisfying agreement between the voltage and current profile of the SOFC. The mean squared error (MSE) has been adopted as an objective function between the achieved data and the experimental data. For minimizing the MSE, a new modified version of the Stain Bowerbirds Optimization algorithm has been utilized. The proposed design is applied to simulated data and practical data to verify its efficiency. Finally, the robustness and the precision of the presented algorithm are compared and verified by some state of art metaheuristics including basic Satin Bowerbird Optimization algorithm (SBO), Differential evolution algorithms (DE), coRNA-GA, Chaotic Binary Shark Smell Optimization (BSSO), and Swarm Optimizer (SO).
\end{abstract}

Keywords: Solid Oxide Fuel Cell; model estimation; Stain Bowerbirds Optimization algorithm; electrochemical model.

\section{$\underline{\text { FULL TEXT }}$}

(C) 2020 The Authors. Published by ESG (www.electrochemsci.org ). This article is an open access article distributed under the terms and conditions of the Creative Commons Attribution license (http://creativecommons.org/licenses/by/4.0/). 